\title{
$\begin{array}{lllllllllllllllll}\mathbf{K} & \mathbf{O} & \mathbf{M} & \mathbf{U} & \mathbf{N} & \mathbf{I} & \mathbf{K} & \mathbf{A} & \mathbf{T} & \mathbf{Y} & \mathbf{N} & \mathbf{A} & \mathbf{U} & \mathbf{K} & \mathbf{O} & \mathbf{W} & \mathbf{E}\end{array}$
}

KWARTALNIK HISTORII KULTURY MATERIALNEJ 68 (3), 2020

PL ISSN 0023-5881

www.iaepan.edu.pl

the CC BY 4.0 license (https://creativecommons.org/licenses/by/4.0/)

DOI: 10.23858/KHKM68.2020.3.006

\author{
Elżbieta Kowalczyk-Heyman
}

\section{Dwie niepublikowane średniowieczne, antropomorficzne rękojeści noży z Muzeum Narodowego w Krakowie}

\author{
Słowa kluczowe: rękojeści antropomorficzne, XIV w., Polska, Kraków \\ Key words: anthropomorphic handles, fourteenth century, Poland, Cracow
}

W trakcie badań wykopaliskowych prowadzonych w Polsce, poczynając od 1951 r., pozyskano 10 średniowiecznych antropomorficznych rękojeści noży ${ }^{1}$. Na czterech z nich przedstawiono stojące postaci mężczyzn z sokołem na ręku (Szczecin I, Elbląg I, Pułtusk i Cieszyn), na jednej kobietę z tym ptakiem (Toruń), a także zakonnika (Będzin) i duchownego świeckiego z księgą (Elbląg II), dwie postaci mężczyzn z rękami ukrytymi w kieszeni (Bardo, Kraków) oraz kobietę trzymającą na ręku psa (Szczecin II). Okazało się jednak, że w polskich zbiorach muzealnych znajdują się dwie kolejne, nieznane dotąd takie rękojeści. Krótką wiadomość o pierwszej z nich podał Krzysztof Wachowski, wspominając, że Muzeum Narodowe w Krakowie posiada w swoich zbiorach rękojeść noża przedstawiającą postać z sokołem. Autor nie opisał zabytku, nie podał surowca, z jakiego go zrobiono, ani datowania, nie ustalił teź płci postaci $^{2}$. Dzięki uprzejmości pracowników Muzeum ${ }^{3}$ uzyskałam szczegółowe informacje nie tylko na temat tego przedmiotu, ale również drugiej rękojeści noża przedstawiającej kobietę z książką i otrzymałam fotografie obu zabytków. W inwentarzu muzealnym określono je jako rękojeści sztyletów, co jest bardzo mało prawdopodobne.

Na pierwszej rękojeści ${ }^{4}$ wyrzeźbiono mężczyznę trzymającego na prawej ręce drapieżnego ptaka (sokoła), którego karmi lewą ręką (ryc. 1). Jest on ubrany w długą szatę, o prostych fałdach. Między jej skrajem a podstawą, na której stoi, po bokach zaznaczono schematycznie stopy. Na głowie mężczyzna ma rodzaj chusty z węzłem z prawej strony. Takie nakrycie głowy, z węzłem po prawej lub lewej stronie, noszą postacie na rękojeściach znanych z Angers, Skanii, Rygi,

1 W rękojeści te oprawiano zazwyczaj noże, jak się wydaje nie tylko o stołowym przeznaczeniu. Są one również częścią szpil służących do układania włosów oraz łyżeczek (szpatułek) używanych do czyszczenia uszu. W przypadku drugiego znaleziska szczecińskiego jest to cały nóż z inkrustowaną głownią, a w przypadku znalezisk z Barda i Elbląga I zachowały się duże fragmenty głowni, por. Kowalczyk-Heyman E. 2010; Kowalczyk-Heyman E. 2014; Kowalczyk-Heyman E. 2017.

2 Wachowski K. 2013, s. 26.

3 Serdecznie dziękuję pani kustosz Monice Paś za cierpliwość i bardzo szczegółowe odpowiedzi na moje pytania oraz pani Agacie Ralskiej za pomoc w uzyskaniu fotografii obu zabytków.

4 Nr inw. MNK IV-MO-1713.

5 Fotografie tych rękojeści znajdują się w kolejności na stronach: www.gothicivories.courtauld.ac.uk/images/ ivory/5AD9E49C_0178ad37.html (dostęp 25.10.2013); www.gothicivories.courtauld.ac.uk/images/ivory/ 30c89a88_6876a38.html (dostęp 30.06.2015); www.gothicivories.courtauld.ac.uk/images/ivory/1006512e 729fbd46.h.html (dostęp 05.03.2015); www.gothicivories.courtauld.ac.uk/images/ivory/586F5117_67381aaf.html (dostęp 21.10.2013); www.gothicivories.courtauld.ac.uk/images/ivory/b6d8fd37_54370900.html (dostęp 30.03.2012). 

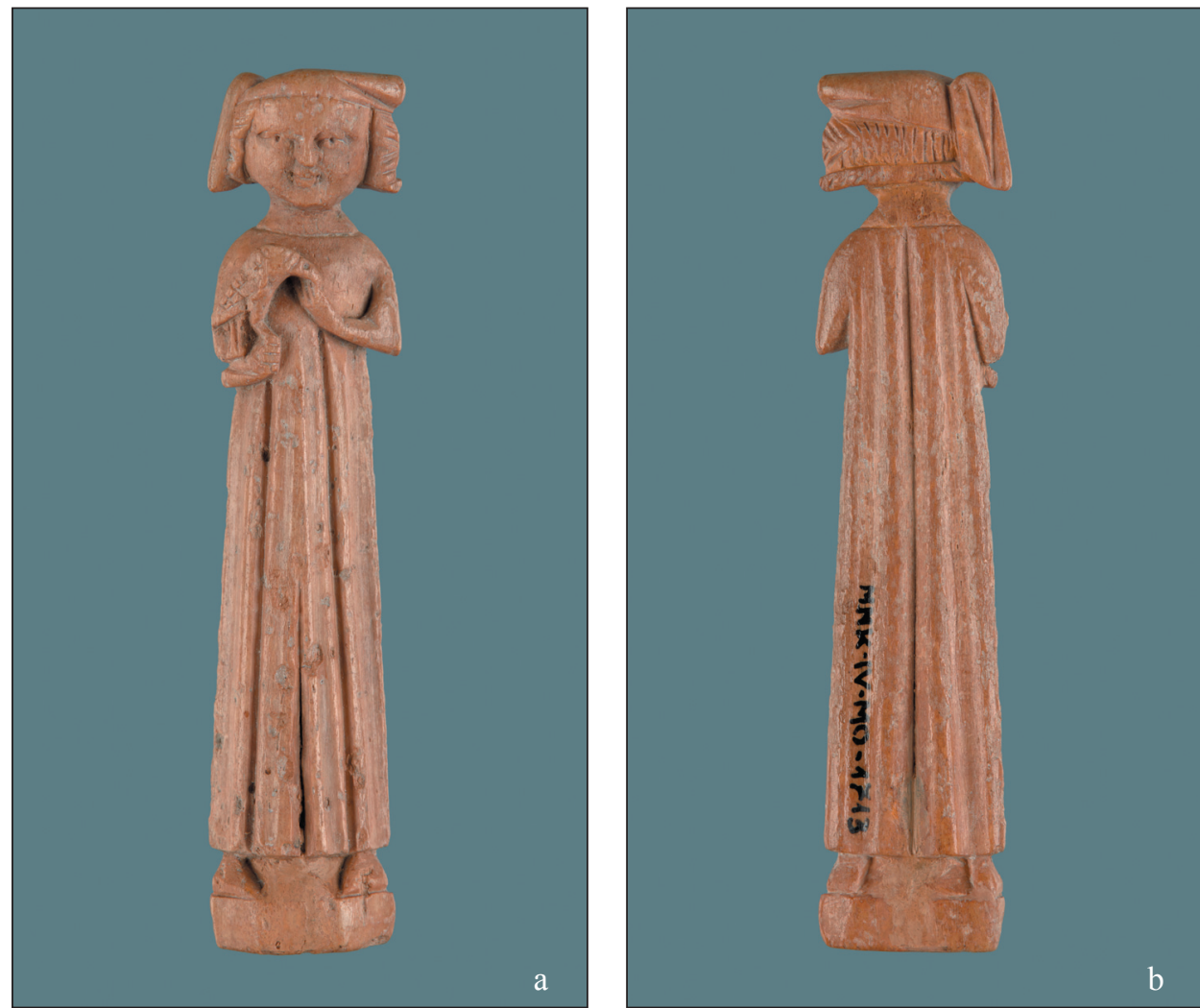

Ryc. 1. Rękojeść noża z mężczyzną trzymającym na prawej ręce sokoła, z początku XIV w.: a - widok z przodu; b — widok z tyłu (Archiwum Fotograficzne Muzeum Narodowego w Krakowie, nr inw. MNK IV-MO-1713)

Fig. 1. A knife handle from the early 14th c.; a man with a falcon sitting on his right arm. $\mathrm{a}$ - the front; $\mathrm{b}$ - the back (the Photographic Archive of the National Museum in Cracow, inventory no. MNK IV-MO-1713)

Schwerinu oraz na rękojeści z podwójnym przedstawieniem kobiety i mężczyzny z Paryża5 Wymienione rękojeści są pozbawione kontekstu archeologicznego, z wyjątkiem rękojeści z Rygi pozyskanej w trakcie badań wykopaliskowych, jednak jej datowanie zmieniało się (wczesny XIII w.; XIII-początek XIV w.; przełom XIII i XIV w. i lata ok. 1250-1350) ${ }^{6}$. Takie samo nakrycie głowy mają mężczyźni na dwóch miniaturach zamieszczonych w powstałym w latach ok. 1300-1340 Codex'ie Manesse. Ukazano na nich grę w szachy oraz nauczyciela z Esslingen? Ułatwia to datowanie wszystkich rękojeści z tym elementem ubioru. Jest też ono zgodne z datowaniem muzealnym, odnoszącym powstanie omawianego zabytku krakowskiego do początku XIV w. Pochodzenie rękojeści nie jest znane. W zbiorach Muzeum pozostaje ona od roku 1891 jako depozyt Akademii Umiejętności.

${ }^{6}$ W kolejności: Hartog E. den. 2012, s. 24, nr 93; Ose I. 2008, s. 576; Holtmann G.F.W. 1993, s. 298; Rybina E.A. 2001, s. 29, ryc. 3:13; Caune A. 1973, s. 396, ryc. na s. 395; Caune A. 2009, s. 20-21, 22, ryc. 4; Bencard M. 1975, s. 54, nr 22-23, www.gothicivories.courtauld.ac.uk/images/ivory/30c89a88_76876a38.html (dostęp 30.06.2015).

7 Codex Manesse. 2017, k. 13, 292v. 
Rękojeść zachowała się w całości, ma jedynie drobne uszkodzenia powierzchniowe oraz podłużne pęknięcie przez podstawę i ok. 1/4 trzonu (które zostało częściowo zaszpachlowane podczas konserwacji). Jej całkowita długość wynosi $8,2 \mathrm{~cm}$, w tym wysokość podstawy $0,7 \mathrm{~cm}$, szerokość $1,8 \mathrm{~cm}$, zaś grubość $0,7 \mathrm{~cm}$. Na dolnej płaszczyźnie podstawy widoczny jest otwór na trzpień noża o długości ok. 0,9 cm, wypełniony „masą plastyczną”. Surowiec, z którego wykonano rękojeść, określono jako kość.

Typ rękojeści z przedstawieniem postaci z sokołem jest najczęściej spotykany na obszarze całej Europy Zachodniej, Środkowej oraz Wysp Brytyjskich, Skandynawii i południowo-wschodniego wybrzeża Bałtyku. Są to nie tylko rękojeści noży, ale również szpil służących do układania włosów. Zebrany przeze mnie zbiór rękojeści tego typu liczy 60 egzemplarzy z wyobrażeniem jednej postaci i dwa egzemplarze z podwójnym. Wyrzeźbione na rękojeściach postaci to zarówno mężczyźni, jak i kobiety. Tylko na kilkunastu z nich ptak siedzi na lewej ręce, zgodnie z regułami sokolnictwa, znacznie zaś częściej na prawej. Niekiedy też ptak siedzi na grzędzie krótkiego lub długiego berła sokolniczego. Symbolika tego przedstawienia jest rozbudowana. Odnosi się ona zarówno do sokoła, jak i do postaci, która go trzyma. Sokół w symbolice średniowiecznej ma wieloznaczny wymiar i zależy od kontekstu, w którym się pojawia. W przypadku omawianego typu rękojeści symboliczne znaczenie ma płeć postaci, która trzyma zwierzę, jej pozycja społeczna, ręka (ewentualnie berło sokolnicze), na której siedzi ptak, ale także inne elementy, takie jak karmienie ptaka, pęta itp. Nie bez znaczenia jest też prestiżowa rola polowań z tymi ptakami ${ }^{8}$.

Oprócz podstawowego rekwizytu, jakim jest ptak, na rękojeściach tego typu pojawiają się inne rekwizyty, w tym także inne gatunki zwierząt: wiewiórka siedząca na barku kobiety lub pies siedzący u stóp postaci, oraz dodatkowy element oporządzenia — torba sokolnicza. Postaci z reguły karmią ptaka drugą ręką lub ptak pobiera pokarm z ręki, na której siedzi. Niekiedy postać w drugiej ręce trzyma poidełko, interpretowane również jako przynęta, bądź drugą rękawicę sokolniczą. Wyjątkowo postać gładzi ptaka po głowie.

Druga rękojeść noża ${ }^{9}$ przedstawia kobietę trzymającą w ugiętych w łokciach rękach, pośrodku torsu, prostokątny rekwizyt (ryc. 2) ${ }^{10}$. Prawą ręką podtrzymuje go od dołu, lewa zaś spoczywa na górnej części. Na karcie inwentarzowej początkowo określono go jako „rodzaj tablicy lub księgi”, następnie jako psalterium, czyli instrument muzyczny z grupy chordofonów szarpanych, na co nie znajduję uzasadnienia. Skłaniam się do identyfikacji tego rekwizytu jako księgi. Jej okładka jest ozdobiona dwoma lekko ukośnymi, równoległymi półwałkami. Na polu między nimi są nawiercone dwa otworki. Podobne zdobienie zastosowano także na rekwizytach widocznych na innych rękojeściach tego typu (o których poniżej).

Kobieta stoi na niewysokiej podstawie. Ubrana jest w długą suknię z niewielkim, płaskim dekoltem i z ukośnie pofałdowaną dolną częścią, upiętą na prawym biodrze. Suknia ma krótkie, rozcięte rękawy, kończące się nieco poniżej łokcia. Na barkach są one spięte jakimiś ozdobami (broszami). Szeroka fryzura, znacznie wystająca poza obrys głowy, przykryta jest płaskim nakryciem ze skośnym, dookolnym zdobieniem w formie półwałków, okolonym od dołu obramowaniem. Nogi postaci są niewidoczne.

Rękojeść znaleziono w 1891 r. w Krakowie, w obrębie Starego Miasta, podczas kopania fundamentów pod obecny Teatr im. J. Słowackiego, na głębokości 1,5 m. Została ofiarowana Muzeum przez Gminę miasta Krakowa. Jej wysokość wynosi 8,9 cm, w tym podstawy 0,4 cm, szerokość $2,4 \mathrm{~cm}$, a grubość $0,9 \mathrm{~cm}$. Do podstawy przylega od dołu niekształtny fragment su-

8 Por. Kowalczyk-Heyman E. 2014, s. 630-631.

9 Nr inw. MNK IV-MO-1511.

${ }_{10}$ Fotografia rękojeści znajduje się na stronie Muzeum Narodowego w Krakowie: https://zbiory.mnk.pl/pl/ wyniki-wyszukiwania?phrase= $=$ sztylet (dostęp 14.05.2020). 

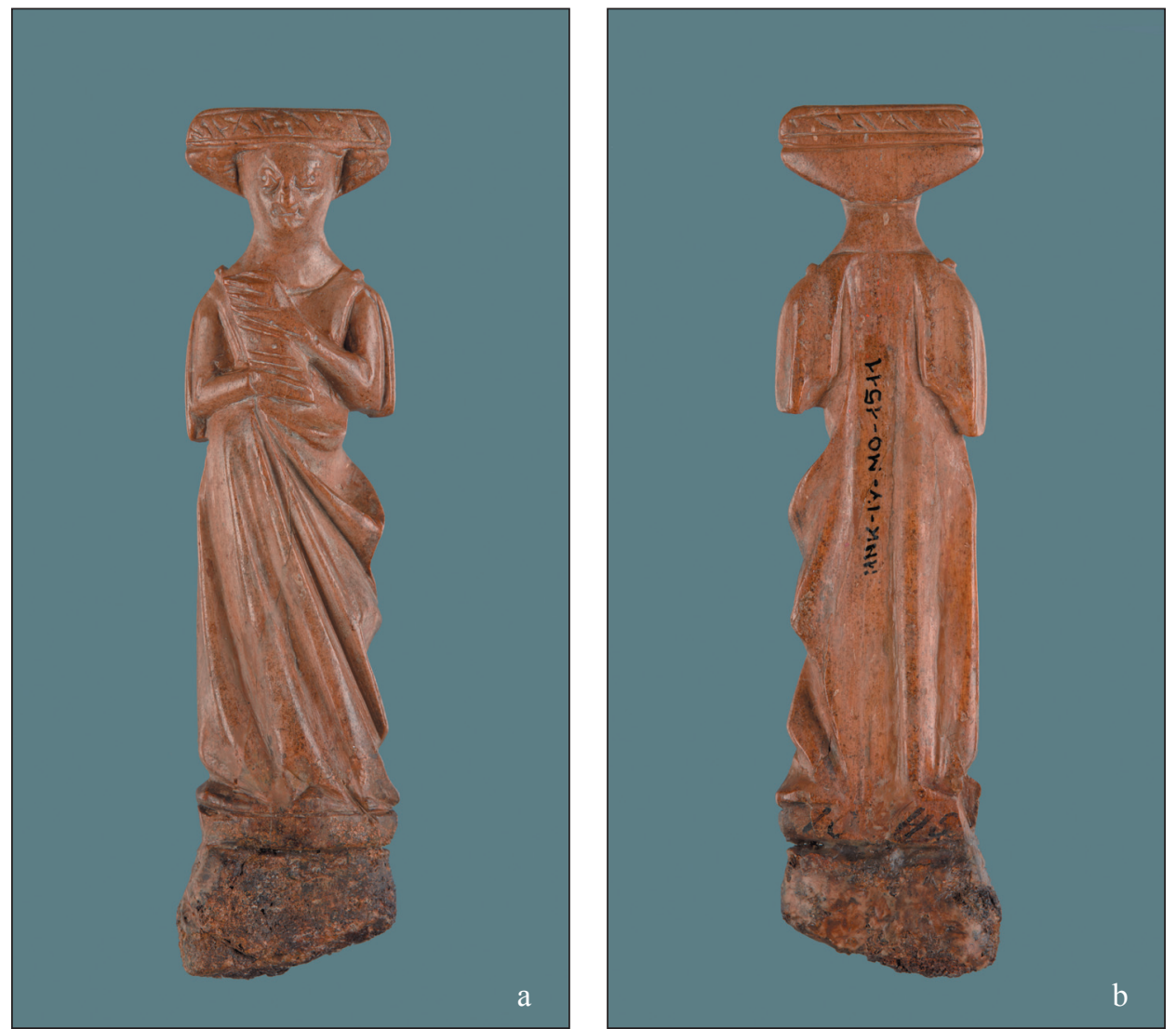

Ryc. 2. Nieukończona rękojeść noża z kobietą trzymającą w obu rękach książkę, z XIV w.: $\mathrm{a}$ - widok z przodu; $\mathrm{b}$ - widok z tyłu (Archiwum Fotograficzne Muzeum Narodowego w Krakowie, nr inw. MNK IV-MO-1511)

Fig. 2. Un unfinished knife handle from the 14th c. a woman holding a book in her hands: $\mathrm{a}$ - the front; $\mathrm{b}$ - the back (the Photographic Archive of the National Museum in Cracow, inventory no. MNK IV-MO-1511)

rowca o długości 1,6 cm i szerokości 2,6 cm. Łączna długość zabytku wynosi zatem 10,5 cm. Na rękojeści widoczne są przebarwienia oraz zaszpachlowane drobne uszkodzenia powierzchniowe i pęknięcia.

Najistotniejsze jest jednak wzdłużne pęknięcie z odgałęzieniem, idące na długości ok. $7,5 \mathrm{~cm}$ przez ową niekształtną część surowca i trzon rękojeści aż po lewą rękę postaci. W dolnej części jest ono zabezpieczone kitem. Surowiec określono jako kość lub poroże jelenia ${ }^{11}$.

W rysunku postaci zwraca uwagę twarz. Charakteryzują ją duże, wypukłe oczy, z wyraźnymi, nawierconymi źrenicami oraz duży nos i wypukłe usta z uniesionymi do góry kącikami. Urzeźbienie to najbardziej przypomina rysy twarzy kobiety trzymającej na ręku psa na rękojeści noża z Neu-Isenburga (Essen) $)^{12}$.

${ }^{11}$ Ta druga możliwość jest poprawna, co stwierdziła z autopsji archeozoolog, dr Anna Gręzak z Instytutu Archeologii UW.

12 www.gothicivories.courtauld.ac.uk/images/ivory/8c43a5c2_016e3062.html (dostęp 11.07.2014). 
W zebranym przeze mnie zbiorze znajduje się 10 innych egzemplarzy tej kategorii zabytków, na których zrealizowano ten sam temat, wszystkie $\mathrm{z}$ wizerunkami kobiet ${ }^{12}$. Dwa z nich to rękojeści noży (Paryż i Mahón), ale o odmiennym rysunku postaci ${ }^{13}$. Pozostałe to rękojeści szpil z całkowicie lub częściowo zachowanymi kolcami (z Antwerpii, Liège, Brugii, Gandawy, Hargicourt, Saint-Denis ${ }^{14}$ i Eilean Donan w Szkocji) i jedna szpatułka (z Paryża) ${ }^{15}$. Do produkcji tej grupy zabytków wykorzystano zarówno kość, jak i kość słoniową, ale nie w każdym przypadku zostało to jednoznacznie określone. Ich datowanie odnoszone jest najczęściej do XIV w. lub do jego faz. Część wyobrażeń jest bardzo podobna do przedstawienia na rękojeści noża z Krakowa. Różnica polega na tym, że w odróżnieniu od noży przyrządy te (tzn. szpile i szpatułki), sądząc z opublikowanej dokumentacji ikonograficznej, były wykonane z jednego kawałka surowca. Wyklucza to uznanie rękojeści z Krakowa za część takiego właśnie przedmiotu — szpili lub szpatułki. Kształt podstawy wskazuje, że miała być w niej zapewne osadzona głownia noża. Jej datowanie odniesiono do pierwszej ćwierci XV w. Sądzę jednak, że powstała w XIV stuleciu.

Badacze nie są zgodni co do identyfikacji rekwizytu trzymanego przez kobiety ma wymienionych rękojeściach. Większość opowiada się za książką ${ }^{16}$, ale pod uwagę brane jest także pudełko. W przypadku szpil z Antwerpii, Liège i Brugii dopuszczono, że prawdopodobnie to puszki Pandory. Ponieważ osiem zabytków to szpile i szpatułka, czyli przybory toaletowe o intymnej wymowie, to być może należałoby rozważyć, czy trzymany przez kobiety rekwizyt nie jest Minnekästchen — czyli tzw. relikwiarzem miłości, w kulturze dworskiej pojemnikiem przeznaczonym na drobne upominki i pamiątki od lub dla kochającej osoby.

Najbardziej interesującym elementem omawianego zabytku jest ów niekształtny, nieobrobiony fragment surowca. Jest on oddzielony od podstawy dookolnym nacięciem. Nie sposób jednak stwierdzić, czy zamierzano go odciąć, czy też wyrzeźbić z niego nasadę, służącą do umocowania obejmy zapobiegającej wyłamaniu trzpienia noża. Na skutek pęknięcia materiału dokończenie rękojeści przerwano, a ją samą porzucono. Fakt ten ma bardzo istotne znaczenie w rozważaniach nad miejscami produkcji rękojeści antropomorficznych. Dowodzi bowiem, że dotychczasowe, powszechne przekonanie o ich wytwarzaniu w warsztatach północnoniemieckich, północnofrancuskich, włoskich i angielskich, nie oddaje rzeczywistości. Podobnie rzecz się ma z przypuszczeniem, że rozprzestrzenienie się tego typu rękojeści następowało za pośrednictwem kupców hanzeatyckich lub duńskich ${ }^{17}$. Miejsce znalezienia niedokończonej rękojeści

12 Jedynie w przypadku rękojeści szpatułki z Paryża z niezrozumiałych powodów uznano, że jest to młodzieniec (youth), por.: www.gothicivories.courtauld.ac.uk/images/ivory/6B9CE00_ee7f7da0.html (dostęp 15.07.2017).

13 cartelen.louvre.fr/cartelen/visite?srv=car_not_frame\&idNotice=28724\&langue=en (dostęp 31.05.2013); www.gothicivories.courtauld.ac.uk/images/ivory/68cb2aad_a7d22b8e.html (dostęp 30.06.2015).

14 Ma utrąconą górną część trzonu.

15 Podaję odniesienia do najbardziej dostępnych fotografii zabytków. W kolejności są to: www.gothicivor ies.courtauld.ac.uk/images/ivory/F0C909CF_b095338c.html (dostęp 30.03.2012); www.gothicivories.courtauld .ac.uk/images/ivory/ecdf9ccd_1138496f.html (dostęp 23.05.2013); www.gothicivories.courtauld.ac.uk/images/ ivory/34cf85f2_8702eec9.html (dostęp 08.11.2013); Bayard D., Mantel E. 1989, s. 179-180, ryc. 10:1; www.gothicivories.courtauld.ac.uk/images/ivory/6B9CE00_ee7f7da0.html (dostęp 16.07.2017); www.gothicivories.court auld.ac.uk/images/ivory/53f2fc3d_50147591.html(dostęp 03.09.2015); www.facebook.com/Eileandonancastle1/ posts/10155025945787888:0 (dostęp 21.07.2017).

16 Du Sommerard książkę tę określił jako le livre d'heures — Księgę godzin, średniowieczny modlitewnik przeznaczony dla osób świeckich, zawierający m.in. modlitwy na określone godziny, święta itp. (du Sommerard E. 1883, s. 87, nr 1112).

${ }_{17}$ Por. Leciejewicz L. 1974, s. 186-188; Holtmann G.F.W. 1993, s. 323-329; Marcinkowski M. 2005/2006, s. 363-364; Wachowski K. 2013, s. 26; Roeder M. 2016, s. 41. Inny badacz, M.D. Howe (1983, s. 150), zwrócił jedynie uwagę na rolę Bałtyku w obrocie handlowym (Howe M.D. 1983, s. 150). 
dowodzi, że warsztaty te znajdowały się również w Europie Środkowej, dowodnie w Polsce. Ponadto, porównanie stylistyki i precyzji wykonania omawianej rękojeści z innymi zabytkami tego typu skłania do zaliczenia jej do grupy wyrobów o dość wysokim poziomie wykonania. Dlatego też określenie miejsca produkcji obu rękojeści jako Francja, w przypadku drugiej rękojeści należy zweryfikować negatywnie.

Adres Autorki:

prof. dr hab. Elżbieta Kowalczyk-Heyman

ekowalczyk@uw.edu.pl

https://orcid.org/0000-0001-8001-9497

\section{BIBLIOGRAFIA}

Bayard Didier, Mantel Etienne. 1989, La maison forte de "La Cologne" a Hargicourt (Aisne). Etude du mobiler, „Revue Archeologique de Picardie”, nr 3-4, s. 141-182.

Bencard Mogens. 1975. Om et middelalderligt knivskaft fra Ribe, [w:] Fra Ribe Amt, t. 19: Festskrift til H. K. Kristensen, Ribe, s. 35-61.

Caune Andris. 1973. Raboty rižskoj ekspedicii, [w:] Acheologičeskie otkrytija 1972 goda, Moskva, s. 394-396.

Caune Andris. 2009. Archäologische Zeugnisse von den Kontakten Rigas mit den westeuropäischen Ländern und Alt-Russ im 13.-14. Jh., [w:] The Hansa Town Riga as mediator between East and West, red. A. Caune, I. Ose, Riga, s. 19-27.

Codex Manesse. 2017. Codex Manesse, Universitätsbibliothek Heidelberg, digi.ub.uni-heidelberg.de/ digit/cpg484/ (dostęp 02.09.2017).

Holtmann Gerhard Folke Wulf. 1993. Untersuchung zu mittelalterlichen und frühneuzeitlichen Messern, Göttingen.

Howe Martin D. 1983. A medieval Knife Handle from Crowland, Lincolnshire, „Medieval Archaeology", t. 27, s. 146-150.

Kowalczyk-Heyman Elżbieta. 2010. Anthropomorph verzierte mittelalterliche Messergiffe in Polen, „Questiones Medii Aevi Novae”, vol. 15, s. 241-282.

Kowalczyk-Heyman Elżbieta. 2014. Znalezisko kolejnej średniowiecznej rękojeści antropomorficznej w Polsce, „Kwartalnik Historii Kultury Materialnej”, R. LXII, nr 4, s. 625-635.

Kowalczyk-Heyman Elżbieta. 2017. Kilka uwag o warsztacie naukowym na podstawie artykułu o średniowiecznym nożu z rękojeścią antropomorficzna ze Szczecina, „Kwartalnik Historii Kultury Materialnej", R. LXV, nr 4, s. 507-512.

Leciejewicz Lech. 1974. O pochodzeniu rogowej rzeźby ze Wzgórza Zamkowego w Szczecinie, [w:] Studia Archaeologica Pomeranica, red. F. Lachowicz, Koszalin, s. 177-188.

Marcinkowski Mirosław. 2005/2006. Człowiek ukryty w kości —średniowieczne rzeźbione rękojeści noży z Elblaga na tle europejskim, „Materiały Zachodniopomorskie. Nowa seria”, t. II/III, z. 1, s. $359-373$.

Ose Ieva. 2008. Einige Zeugnise vom Lebensstil der reichen Bürger in Riga im 13.-15. Jahrhundert, [w:] Lübecker Kolloquium zur Stadtarchäologie im Hauseraum, [t.] VI: Luxus und Lifestyle, Lübeck, s. 569-583.

Roeder M. 2016. Der mit dem Falken jagt, „Archäeologie in Deutschland”, z. 2, s. 41.

Rybina Elena Aleksandrovna. 2001. Frühe 'Joint Ventures'. Die Beziehungen Novgorods in Ostseeraum, [w:] Novgorod. Das mittelalterlische Zentrum und sein Umland im Norden Russlands, Studien zur Siedlungsgeschichte und Archäologie der Ostseegebiete, t. 1, red. M. Müller-Wille $\mathrm{i}$ in., Neumünster, s. 291-308.

Sommerard Edmond du. 1883. Catalogue et desccription des objets d'art de l'antiquité du moyen âge et de la Renaissance, exposées au Musée de Cluny, Paris.

Wachowski Krzysztof. 2013. Emblemata mediaevalia profana. Przykład Polski, Wrocław. 


\section{Strony internetowe}

http://cartelen.louvre.fr/cartelen/visite? $\mathrm{srv}=$ car_not_frame\&idNotice $=28724 \&$ langue $=$ en $($ dostęp 31.05.2013).

https://www.facebook.com/Eileandonancastle1/posts/10155025945787888:0 (dostęp 21.07.2017).

http://www.gothicivories.courtauld.ac.uk/ (dostęp 30.03.2012-21.07.2017).

https://zbiory.mnk.pl/pl/wyniki-wyszukiwania?phrase=sztylet (dostęp 14.05.2020).

Two unpublished mediaeval anthropomorphic knife handles from the National Museum in Cracow

The article is the first publication on two mediaeval anthropomorphic knife handles from the collection of the National Museum in Cracow, never described in the literature so far. One of them shows a man feeding with his left hand a falcon sitting on his right arm (fig. 1). This item has no archaeological context. The other artefact shows a woman holding in her hands an object which is usually interpreted as a book, or less frequently as a box (fig. 2). Both motifs, especially the former one, are often found in knife handles and hair parters dating from between the 2 nd half of the 13th and the 14th c. Considering the style of the man's headgear, the first item can be assumed to have been made in the first half of the 14th $\mathrm{c}$. The other handle can be dated broadly to the 14th c.; and it is more interesting to investigate. It was found in Cracow at the end of the 19th c., during construction works. It had not been finished: there is unworked raw material at the bottom of the figure. The carving of this artefact was abandoned as it had cracked lengthwise. This find proves that handles of that type were made not only in Western Europe, as is widely assumed, but also in Central Europe, including Poland.

Proofread by Izabela Szymańska 